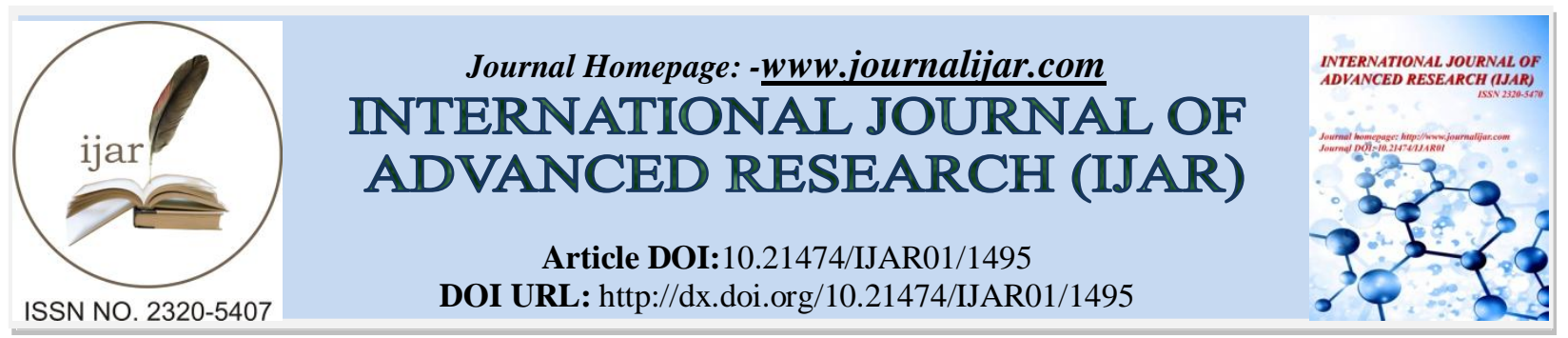

RESEARCH ARTICLE

\title{
ACHIEVEMENT OF THERAPEUTIC GOALS IN A SAMPLE OF IRAQI ADULTS WITH TYPE 2 DIABETES MELLITUS.
}

Dr. Mahmood Shakir Khudhair (M.B.Ch.B, F.I.B.M.S).

Assistant Professor in Medicine and Endocrinology, Al Nahrain College of Medicine, Kadhimia-baghdad-iraq.

\section{Manuscript Info}

Manuscript History

Received: 16 July 2016

Final Accepted: 16 August 2016

Published: September 2016

Key words:-

Type 2 DM, HbA1c, LDL-C, therapeutic goals; Iraq.

\section{Abstract}

Background:- Diabetes mellitus is a chronic illness that requires continuing medical care and ongoing patient self-management education.Achieving glycemic goals help to prevent acute complications and to reduce the risk of long-term complications.

Objective:- to evaluate a sample of Iraqi patients with type 2 diabetes, regarding percentage of patients who achieve the therapeutic goals of treatment.

Patients and Methods:-This was a cross sectional study of 200 patients with type 2 diabetes in Al-Kadhimia Teaching Hospital/Baghdad city. This study evaluated the achievement of target goals for glucose,lipid and blood pressure as suggested by theAmerican Diabetes Association guidelines.

Results:-The mean $\mathrm{HbA1c}$ was $9.4 \pm 2.6 \%$ and the percentage of patients achieved glycemic control (HbA1c <7\%) was only $27 \%$. And about $55 \%$ of hypertensive patients achieved the recommended target. The percentages of those who achieved the target value for dyslipidemia were $73.5 \%$ for low density lipoprotein cholesterol, $29 \%$ for triglyceride, and only $37.5 \%$ for high density lipoprotein cholesterol.

Conclusion:-The results of this study of Iraqi patients with type 2 diabetes mellitus demonstrated that $73 \%$ of cases with hyperglycemia, $45 \%$ of cases with hypertension, and $60 \%$ to $70 \%$ of cases with dyslipidemia had not reached their targets.

\section{Abbreviations:-}

- HbA1c :Glycated hemoglobin

- DM :Diabetes mellitus

- CV :Cardiovascular

- BP :Blood pressure

- BMI :Body mass index

- $\quad$ TG :Triglyceride

- $\quad$ LDL-C :Low density lipoprotein cholesterol

- HDL-C:High density lipoprotein cholesterol 


\section{Introduction:-}

Type 2 diabetes mellitus (T2DM) is one of the most common health problems facing mankind and is a major public health problem. The pathogenesis of T2DM is complex and involves the interaction of genetic and environmental factors. From a pathophysiologic standpoint, persons with T2DM consistently demonstrate three cardinal abnormalities: resistance to the action of insulin in peripheral tissues, particularly muscle and fat but also liver,defective insulin secretionparticularly in response to a glucose stimulus and increased glucose production by the liver. ${ }^{[1]}$

Diabetes is an important public health problem, one of four priority noncommunicable diseases (NCDs) targeted for action by world leaders. Both the number of cases and the prevalence of diabetes have been steadily increasing over the past few decades ${ }^{[2]}$.

In addition to the 415 million adults who are estimated to currently have diabetes, there are 318 million adults with impaired glucose tolerance, which puts them at high risk of developing the disease in the future. ${ }^{[3]}$.

The increasing prevalence of type-2 diabetes, which is attributable to a growing population, an increase in life expectancy ${ }^{[4]}$.Hypertension is the most frequent $(90 \%)$ among the co-morbid disease conditions ${ }^{[5]}$ and further increases the risk for disease and treatment related complications ${ }^{[6]}$. The combination of both hypertension and diabetes accelerates the progression of diabetes related complications such as diabeticnephropathy, retinopathy, left ventricular hypertrophy, and diastolic heart failure and doubles the risk of stroke, CV and all-cause mortality as compared to non-diabetic patients with hypertension ${ }^{[7]}$.

\section{Therapeutic goals :-}

The aim of treatment is to relieve the symptoms of hyperglycemia and to achieve as near normal metabolism as is practicable. The nearer the body weight approaches the ideal level and the closer the blood glucose is kept to normal, the more the total metabolic profile is improved and the lower the incidence of vascular disease and specific diabetic complications. Excellent glycaemic control may also retard the progression of pancreatic $\beta$-cell failure. ${ }^{[8]}$

\begin{tabular}{|l|l|}
\hline \multicolumn{2}{|l|}{ Box 1: Treatment Goals for Adults with Diabetes ${ }^{[8]}}$. \\
\hline INDEX & GOAL \\
\hline Glycemic control & $<7.0$ \\
\hline A1C & $4.4-7.2 \mathrm{mmol} / \mathrm{L}(80-130 \mathrm{mg} / \mathrm{dL})$ \\
\hline $\begin{array}{l}\text { Preprandial capillary plasma } \\
\text { glucose }\end{array}$ & $<10.0 \mathrm{mmol} / \mathrm{L}(<180 \mathrm{mg} / \mathrm{dL})$ \\
\hline $\begin{array}{l}\text { Peak postprandial capillary plasma } \\
\text { glucose }\end{array}$ & $<140 / 90$ \\
\hline Blood pressure & \\
\hline Lipids & $<2.6 \mathrm{mmol} / \mathrm{L}(<100 \mathrm{mg} / \mathrm{dL})$ \\
\hline Low-density lipoprotein & $>1.1 \mathrm{mmol} / \mathrm{L}(>40 \mathrm{mg} / \mathrm{dL})$ for male patients \& $>1,3 \mathrm{mmol} / \mathrm{L}(>50 \mathrm{mg} / \mathrm{dL})$ \\
\hline High-density lipoprotein & for female patients $)$ \\
\hline Triglycerides & $<1.7 \mathrm{mmol} / \mathrm{L}(<150 \mathrm{mg} / \mathrm{dL})$ \\
\hline
\end{tabular}

\section{Aim of the study:}

The purpose of this study is to evaluate patients with type 2 diabetes, regarding percentage of patients who achieve the targets of glycemic control, blood pressure, lipids, \& body weight.

\section{Patients\&Methods:-}

This cross sectional study was performed in Al-Kadhimia Teaching Hospital medical city in Baghdad. The patients were collected by random sampling, from diabetic population who attend the diabetes clinic and medical ward in this hospital, patient with type 1 diabetes mellitus were excluded. Patient who were registered as having type 2 diabetes, \& receiving diabetes treatment selected randomly excluding those who were newly diagnosed within six months.

A total of 200 patients were analyzed (106 women, 94 men). Patients' clinical data were recorded and included subject gender, age, duration of diabetes, diabetes treatment method, and the number of antihypertensive drugs used 
were analyzed.Body mass index (BMI) and blood pressure were measured.BMI was calculated by dividing the measured weight $(\mathrm{kg})$ by the squared height $(\mathrm{m} 2)$.

Glycated hemoglobin (HbA1c), pre-prandial \& postprandial blood glucose level, and lipid profile were checked, based on these results, each goal was investigated.,

Diabetes management goals were HbA1c less than $7 \%$, pre-prandial blood glucose level $<130 \mathrm{mg} / \mathrm{dL}$, postprandial blood glucose level $<180 \mathrm{mg} / \mathrm{dL}$, systolic blood pressure $<140 \mathrm{~mm} \mathrm{Hg}$, and diastolic blood pressure $<90 \mathrm{~mm} \mathrm{Hg}$. LDL-C less than $100 \mathrm{mg} / \mathrm{dL}$, triglycerides less than $150 \mathrm{mg} / \mathrm{dL}$, HDL-C greater than $40 \mathrm{mg} / \mathrm{dL}$ in men, and over 50 $\mathrm{mg} / \mathrm{dL}$ in women were set. The patient management goals were established in accordance with the guidelines of the American Diabetes Association ${ }^{[9]}$.

\section{Statistical methods:-}

All data was expressed as mean \pm standard deviation, and Microsoft office excel 2007 was used for entry of data and to perform all statistical analysis.

The comparison among the blood glucose, \&blood pressure, groups were analyzed using t-tests and chi-square tests; with a significance level was set at $\mathrm{P}<0.05$.

\section{Ethical consideration:-}

Informed consent was obtained from all patients enrolled in this study.

\section{Results:-}

\section{Patient characteristics:-}

Among the 200 patients analyzed in this study, 106 were female, and 94 were male.Peak incidence at the $6^{\text {th }}$ decade (Figure 1). The mean patients' age was $59.3 \pm 10.8$, and the mean BMI was $27.7 \pm 5.4 \mathrm{~kg} / \mathrm{m} 2$.

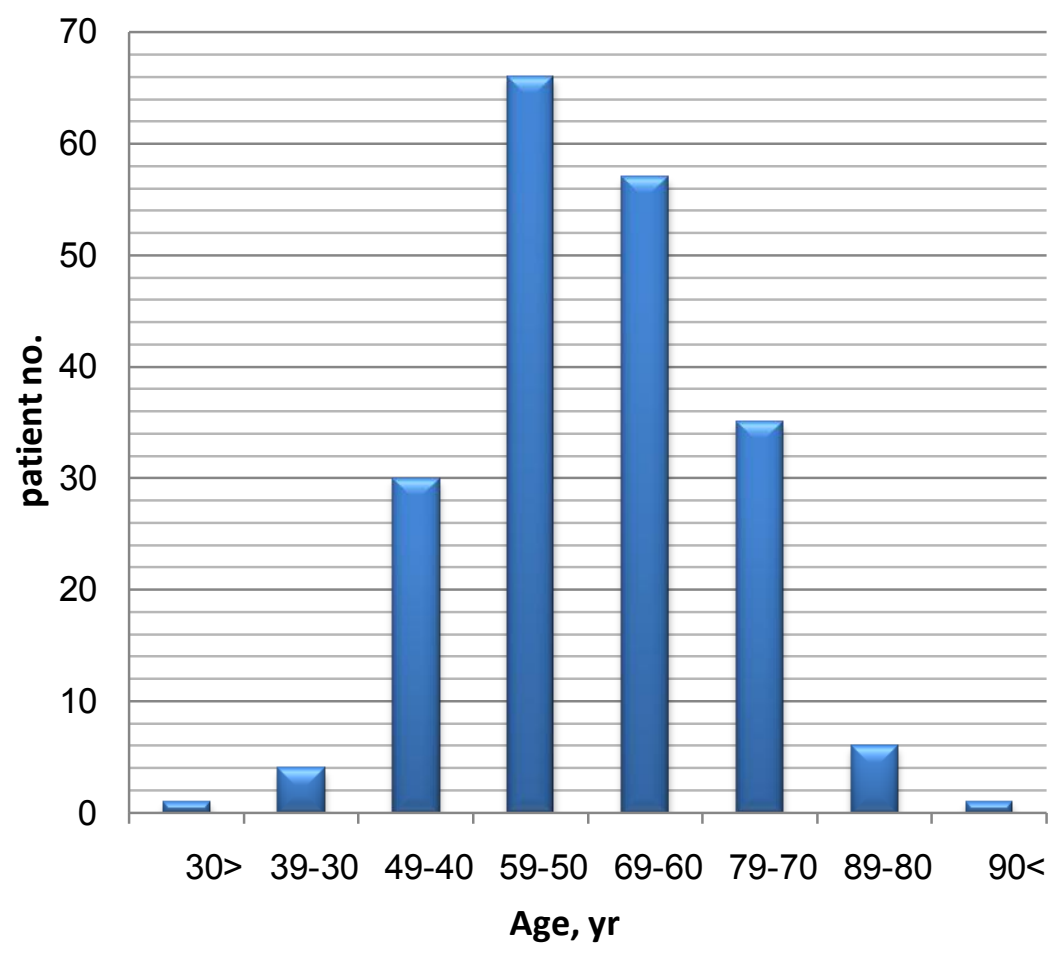

Figure 1:- Age distribution in patient with type 2 diabetes mellitus 
Among the participants, $28.5 \%$ (57 patients) were classified as overweight, possessing a BMI between $25 \& 30$ $\mathrm{kg} / \mathrm{m}^{2}$. And about $31 \%$ of patients classified as obese, having BMI greater than $30 \mathrm{~kg} / \mathrm{m}^{2}$.

Among the patients, $33.0 \%$ had been diagnosed with diabetes duration more than ten years. In addition $54.5 \%$ of patients (109 of the total patients) had been diagnosed with hypertension (Table 1).

Table 1:- Characteristics of the study subjects.

\begin{tabular}{|l|c|c|c|}
\hline \multicolumn{1}{|c|}{ Characteristic } & Men $(n=94)$ & Women $(n=106)$ & Total $(n=200)$ \\
\hline Age, yr & $58.6 \pm 10.2$ & $59.7 \pm 11.3$ & $59.3 \pm 10.8$ \\
\hline BMI, kg/m2 & $25.8 \pm 3.7$ & $29.5 \pm 6.1$ & $27.7 \pm 5.4$ \\
\hline DM duration, yr & $9.2 \pm 6.4$ & $10.2 \pm 7.7$ & $9.7 \pm 7.1$ \\
\hline HbA1c, \% & $9.7 \pm 2.7$ & $9.1 \pm 2.6$ & $171.6 \pm 63.4$ \\
\hline Preprandial glucose & $174.8 \pm 66.1$ & $168.7 \pm 61.5$ & $233.9 \pm 85.98$ \\
\hline postprandial glucose & $234.6 \pm 81.27$ & $1233.4 \pm 90.7$ & $126.3 \pm 15.8$ \\
\hline Blood pressure, mm Hg & \multicolumn{3}{|l|}{} \\
\hline Systolic & $124.04 \pm 13.8$ & $82.7 \pm 8.2$ \\
\hline Diastolic & $82.02 \pm 7.8$ & $93.2 \pm 8.6$ & $93.5 \pm 26.9$ \\
\hline Lipid profile & $89.6 \pm 23.8$ & $97.1 \pm 29.3$ & $207.04 \pm 78.7$ \\
\hline LDL-C, mg/dL & $44.4 \pm 15.6$ & $38.1 \pm 13.1$ & $54.5 \%$ \\
\hline HDL-C, mg/dL & $199.3 \pm 81.6$ & $213.9 \pm 76.1$ & $69.8 \%$ \\
\hline Triglyceride, mg/dL & $37.2 \%$ & \multicolumn{3}{|l|}{} \\
\hline Prevalence of hypertension, \% &
\end{tabular}

*Data are presented as mean \pm standard error.

BMI, body mass index; DM, diabetes mellitus; LDL-C, low density lipoprotein cholesterol; HDL, high density lipoprotein cholesterol.

\section{Blood glucose control:-}

Of the 200 patients who had registered, $27 \%$ had reached their goal of maintaining an HbA1c level less than $7.0 \%$ (Figure 2), $15.5 \%$ were female, \& $11.5 \%$ were male.

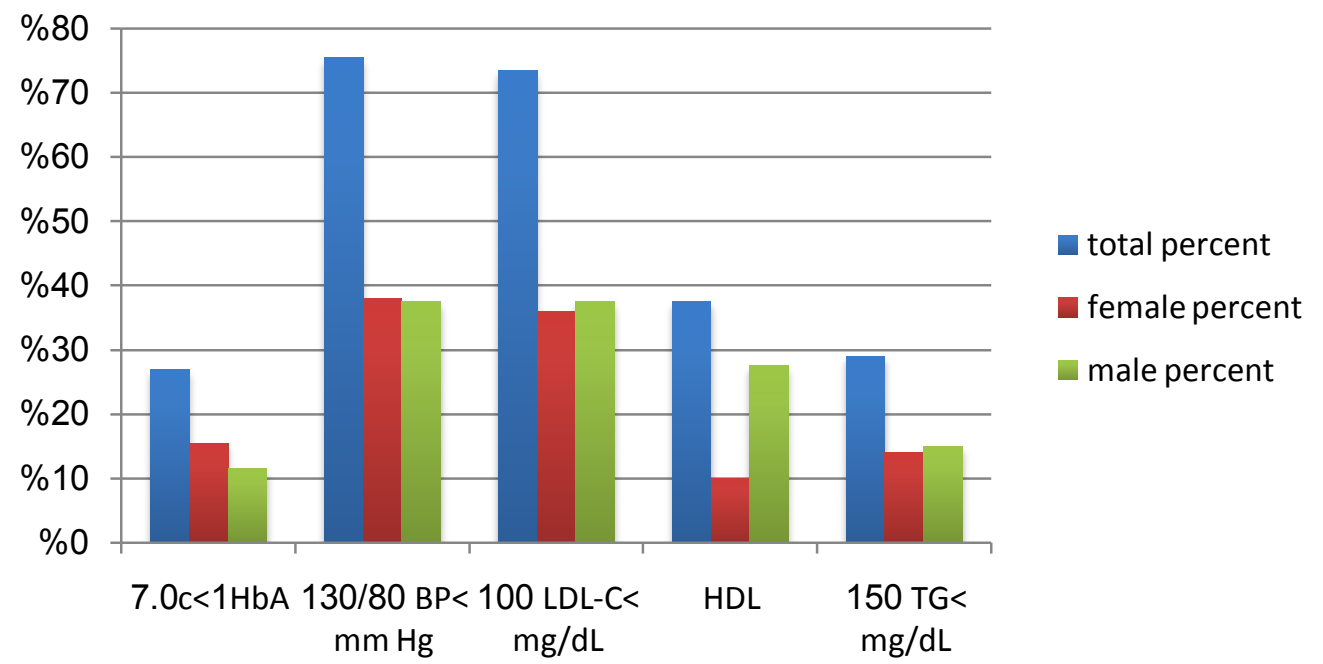

Figure 2:- Proportion of patients reaching the therapeutic goals, (HDL: $>40 \mathrm{mg} / \mathrm{dL}$ in male \& $>50 \mathrm{mg} / \mathrm{dL}$ in female)

Among the 106 female participants, 31 (29.2\%) reached their treatment goal, and among the 94 male participants, 23 $(24.5 \%)$ reached their treatment goal; there was no significant difference between males \& females in achieving glycemic control. ( $\mathrm{P}=0.4)$ (Table 2$)$. 
Table 2:- Characteristics of the study subjects according to their achievement of HbA1c control.

\begin{tabular}{|c|c|c|c|c|}
\hline \multirow{2}{*}{\multicolumn{2}{|c|}{ Characteristic }} & \multicolumn{2}{|c|}{ A1c } & \multirow[t]{2}{*}{ P. value } \\
\hline & & $\leq 7 \%$ & $>7 \%$ & \\
\hline \multirow[t]{2}{*}{ Sex } & Female & 31 & 75 & \multirow[t]{2}{*}{0.4} \\
\hline & Male & 23 & 71 & \\
\hline \multicolumn{2}{|c|}{ BMI, kg/m2 } & $27.3 \pm 5.5$ & $27.9 \pm 5.4$ & 0.47 \\
\hline \multicolumn{2}{|c|}{ Duration, yr } & $7.9 \pm 7.2$ & $10.4 \pm 6.9$ & 0.029 \\
\hline
\end{tabular}

* Data are presented as mean \pm standard error or number.

The average time since diagnosis of the patient group who reached their treatment goal was $7.9 \pm 7.2$ years and the average time since diagnosis of the patient group who failed to reach their treatment goal was 10.4 \pm 6.9 years. The shorter was the time since diagnosis, the higher was the treatment success rate $(\mathrm{P}=0.029)$ (Table 2).

Of the 200 patients who had registered, $28 \%$ (15\% of them were female, $13 \%$ male) had reached their goal of maintaining a pre-prandial blood glucose level less than $130 \mathrm{mg} / \mathrm{dL}$. Also $36 \%$ of the patients had a postprandial glucose level of less than $180 \mathrm{mg} / \mathrm{dL}$.

In this study about $31 \%$ of the patients received insulin, $19.5 \%$ treated with metformin, $28 \%$ using glibenclemide, $20 \%$ of them use combination therapy (metformin + glibenclemide), \& $1.5 \%$ use other form of combination therapy: metformin\&repaglinide,(Figure3).

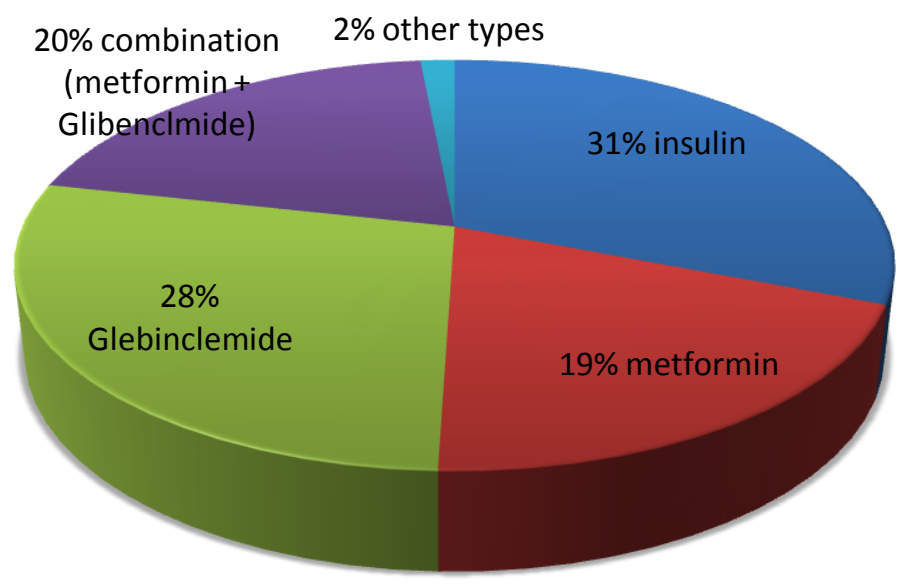

Figure 3:- Types of treatment in patient with type 2 DM

\section{Blood pressure control:-}

Among the participants in this study, 54.5\% ( $\mathrm{n}=109)$ had hypertension, among which 35 patient were male \& 74 patient were female.and55\% of these patients had controlled blood pressure (Figure 4). 


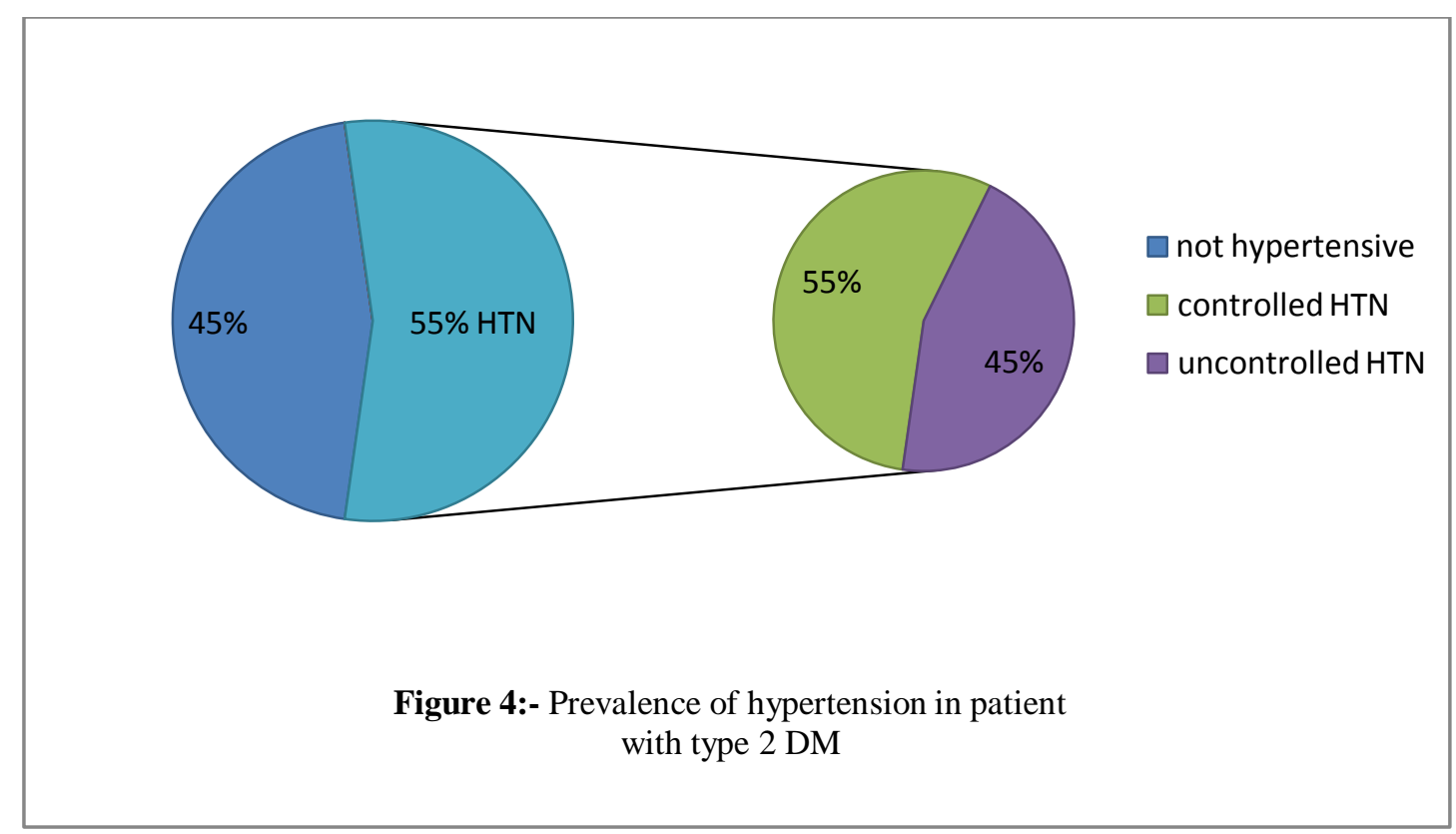

About $78 \%$ of the participants was taking one type of antihypertensive drugs, and $22 \%$ were taking two types of antihypertensive drugs.

About $75 \%$ of the patient who had controlled blood pressure was taking one type of antihypertensive medications, the rest $(25 \%)$ with two types. The percentage of treatment success in patients who were taking only one type of antihypertensive drug was high.

Among the 35 male participants, 16 (45.7\%) reached their treatment goals, and among the 74 female participants, 44 $(59.5 \%)$ reached their treatment goals. There was no significant difference between males \& females regarding controlling blood pressure $(\mathrm{P}=0.17)$.

\section{Lipid control:-}

The percentage of patients who reached their serum lipid level goals of LDL-C $(<100 \mathrm{mg} / \mathrm{dL})$, triglycerides $(<150$ $\mathrm{mg} / \mathrm{dL}$ ), and HDL-C (>40 mg/dL in males, $>50 \mathrm{mg} / \mathrm{dL}$ in females) were $73.5 \%, 29 \%$, and, $37.5 \%$ respectively (Figure 5).

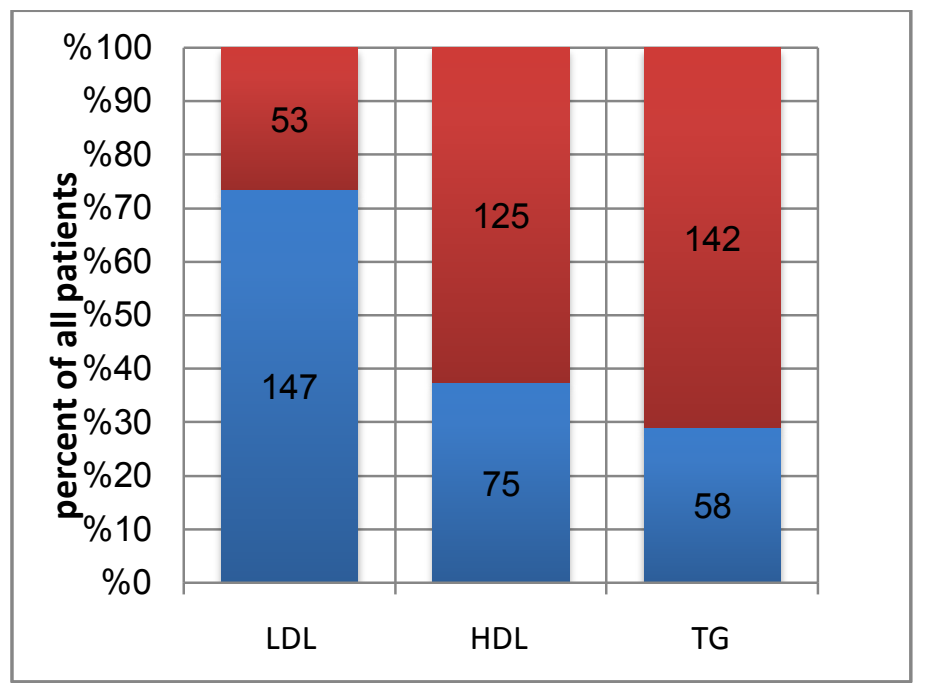

Figure 5:- The percentage of patients who reached their serum lipid level goals of LDL-C ( $<100 \mathrm{mg} / \mathrm{dL})$, HDL-C $(>40 \mathrm{mg} / \mathrm{dL}$ in males, $>50 \mathrm{mg} / \mathrm{dL}$ in females), andtriglycerides $(<150 \mathrm{mg} / \mathrm{dL})$, the blue part of the column. 


\section{Eye and foot care:-}

About $68.5 \%$ of the patients did n't observe there foot for any complications, the rest $31.5 \%$ did annual foot care, among those $20 \%$ were females, $11.5 \%$ were males (Figure 6). Also about 33.5\% of the patients (about 67 of the total number.) performed regular eye examination screening for diabetic retinopathy, $19 \%$ were females, \& $14.5 \%$ were males (Figure 7).
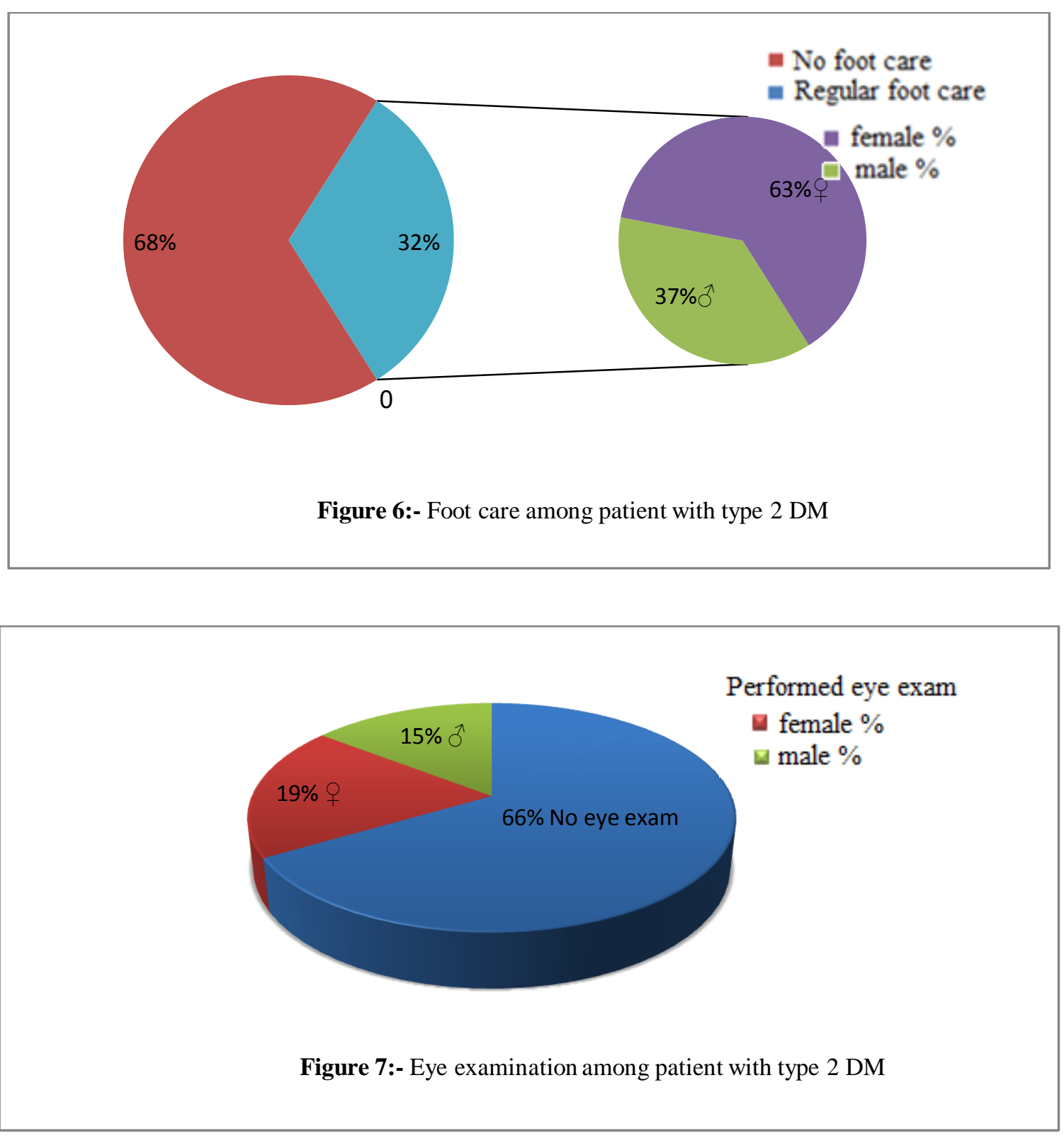

\section{Discussion:-}

T2DM in Iraq has high prevalence, as by STEP survey conducted by ministry of health in $2006,10.4 \%$ of Iraqi adults above 24 year age had high fasting plasma glucose ${ }^{\cdot(10)}$

There is no clear Iraqi national estimate on overall glycemic control and how medical centers and diabetic patients follow the guidelines of treatment and regular follow up to detect complications in type2 DM. 
This present study aims to give an idea about the current situation of management goals of type 2 DM in a sample ofIraqi patients who attend a governmental diabetic clinic in Baghdad who offers only basic follow up and essential medications ,metformin,glibenlamide and insulins.

In this study, only $27 \%$ of patients reached their HbA1c goal of less than $7.0 \%$, which means that nearly three quarters of patient are out of control putting them at high risk for complications and increase the burden of the disease on the society.

When this study was compared with studies from other countries, nearly similar results seen in a report by Akbar ${ }^{[11]}$ In Saudi Arabia, only $27 \%$ of the patients reach target level of glycemic control. In Jordan study by M. Khattabet $a l^{[12]}$ show that about $34.9 \%$ of patients with type $2 \mathrm{DM}$ have HbA1c below $7 \%$. Also reports by Lieblet al. ${ }^{[13]}$ involving data from eight countries based on the European Diabetes Policy Group Guidelines, 31\% had an HbA1c less than $6.5 \%$ and in reports by Sone et al. ${ }^{[14]}$ from Japan, $29.3 \%$ had an HbA1c less than $7.0 \%$.

The results reported by Harris et al. ${ }^{[15]}$ show that $44.6 \%$ of patients have reached the target of and HbA1c less than 7.0\%. In the American National Health and Nutrition Examination Survey (NHANES) ${ }^{\text {16] }}, 57.1 \%$ of patients have reached the target $\mathrm{HbA} 1 \mathrm{c}$ of less than 7.0\%. In study by Korean diabetes association, Kang AY, et al. ${ }^{[17]} 51.8 \%$ have reached their goal of maintaining an HbA1c level less than $7.0 \%$.

When the characteristics of patients who have reached their target for glycemic control and patients who have not reached their target for glycemic control are compared, our study shows no differences in the target success rate comparing males and females, similar to other studies that have shown no differences between men and women,

The results of patients followed in private clinic may be better due to availability of more recent anti diabetic drugs which are not offered in governmental centers.

We can explain the poor glycemic results in this study by lack of educational support for those patients, irregular supply of medications and investigations in the governmental sector.

Regarding increases in BMI on HbA1c ${ }^{[12-13]}$. Unlike that reported by Lee et al. ${ }^{[18]}$, which shows that male have higher control rate, while study by Korean diabetes association, Kang AY, et al. ${ }^{[\mathbf{1 6}]}$ shows that females have the higher control rate in reaching target glycemic control.

In the present study, the mean duration of diabetes in patients who successfully reach their treatment goals was 7.9 \pm 7.2years, and the mean duration in patients who do not reached their treatment goal was $10.4 \pm 6.9$ years. The shorter is the duration of diabetes, the higher is the treatment successrate $(\mathrm{P}=0.029)$ (Table 2). Glycemic control becomes more difficult as diabetes progresses, and the necessity for additional drug actions and the use of insulin increasing.

Of the total participants $54.5 \%(\mathrm{n}=109)$ have hypertension. Amonghypertensive patients, about $55 \%$ reached their target which is higher than the result of Kang AY, et al. ${ }^{[16]}, 32.2 \%$ below the target $130 / 80 \mathrm{~mm} \mathrm{Hg}$.

The patients who reach their serum lipid level goals of LDL-C ( $<100 \mathrm{mg} / \mathrm{dL})$, triglycerides $(<150 \mathrm{mg} / \mathrm{dL})$, and HDL-C (>40 mg/dL in males, $>50 \mathrm{mg} / \mathrm{dL}$ in females) are $73.5 \%, 29 \%$, and, $37.5 \%$ respectively. These results are lower than the $66.3 \%$ for LDL-C, $57.9 \%$ for triglycerides, and $51.8 \%$ for HDL-C reported by Kang AY, et al. ${ }^{[16]}$ but are higher than the $35.7 \%$ for LDL-C reported by Lim et al. ${ }^{[19]}$ in their study on dyslipidemia patients at a tertiary hospital. The results also lower in comparison with that results reported by the NHANES ${ }^{[15]}: 46.6 \%$ triglycerides, and $58.0 \%$ HDL-C. but there is higher success rate in this study regarding the LDL-C which is about $46.5 \%$ by the NHANES ${ }^{[15]}$ which may be explained by increasing use and availability of statins .

\section{Limitation:-}

There are several limitations in this study. This study was performed at one hospital in Baghdad city and the study did not include a large variety or a large number of patients. Therefore, in the future, a larger scale study will be required to establish the success rates and complications in type 2 diabetes patients. 


\section{Conclusions:-}

In conclusion, this study shows that $73 \%$ of cases with hyperglycemia, $45 \%$ of cases with hypertension, and $60 \%$ to $70 \%$ of cases with dyslipidemia have not reached their targets. More research and clinical effort will be required to achieve the targets of hyperglycemia, hypertension, and dyslipidemia.

\section{Disclosure:-}

Authors have no conflict of interests, and the work was not supported or funded by any drug company.

\section{Acknowledgements:-}

I would like to thank laboratory department at Imamainmedical city and community medicine at AlNahraincollege of medicine for their help regarding the investigations and analysis of results respectively.

\section{References:-}

1. Kenneth S. Polonsky and Charles F. Burant .Type 2

DiabetesMellitus.In:ShlomoMelmed,KennethS.Polonsky,P.Reed Larsen et al. WILLIAMS textbook of

Endocrinology. 13th edition.Elsevier; 2016.p.1386.

2. World Health Organization. Executive Summary .Global report on Diabetes.World Health Organization, $2016 .$.

3. International Diabetes Federation.IDF Diabetes Atlas. 7th ed. International Diabetes Federation; 2015.

4. Wild S, Roglic G, Green A, Sicree R, King H: Global prevalence of diabetes:estimates for the year 2000 and projections for 2030. Diabetes Care 2004; 27(5):1047-1053.

5. Bramlage P, Binz C, Gitt AK et al: Diabetes treatment patterns and goal achievement in primary diabetes carestudy protocol and patient characteristics at baseline.CardiovascDiabetology2010, 9:53.

6. Haffner SM, Lehto S, Ronnemaa T, Pyorala K, Laakso M: Mortality from coronary heart disease in subjects with type 2 diabetes and innondiabetic subjects with and without prior myocardial infarction.NEngl $\mathbf{J}$ Med 1998, 339(4):229-234.

7. Zomer E, Liew D, Owen A, et al: Cardiovascularrisk prediction in a population with the metabolic syndrome:Framingham vs. UKPDS algorithms. Eur J PrevCardiol 2014; 21, 3: pp. 384-390.

8. Alvin C.Powers. Diabetes Mellitus: Management and Therapies. In:Dennis L. Kasper,AnthonyS. Fauci,Stephen L. Hauser et al.Harrison' Principles of Internal Medicine.19th edition.McGraw-Hill Education.2015,p 2408.

9. American Diabetes Association. Standards of medical care in diabetes--2016.Diabetes Care Volume 39, Supplement 1, January 2016,S43.

10. Chronic Non-Communicable Diseases Risk Factors Survey InIraq 2006 http://www.who.int/chp/steps/IraqSTEPSReport2006.pdf

11. Akbar, D. H. Low rates of diabetic patients reaching good control targets. Eastern Mediterranean Health Journal 2001, 7: 671-678.

12. MaysaaKhattab, Yousef S. Khader, AbdelkarimAl-Khawaldeh, et al. Factors associated with poor glycemic control among patients with Type 2 diabetes . Journal of Diabetes and Its Complications2010; 24: 84-89

13. Liebl A, Mata M, Eschwege E. Evaluation of risk factors for development of complications in type II diabetes in Europe. Diabetologia 2002; 45:S23-8.

14. Sone H, Kawai K, Takagi H, et al. Outcome of one-year of specialist care of patients with type 2 diabetes: a multi-center prospective survey (JDDM 2). Intern Med 2006; 45:589-97.

15. Harris MI, Eastman RC, Cowie CC, et al. Racial and ethnic differences in glycemic control of adults with type 2 diabetes. Diabetes Care 1999; 22:403-8.

16. Cheung BM, Ong KL, Cherny SS, et al.Diabetes prevalence and therapeutic target achievement in the United States, 1999 to 2006.Am J Med 2009;122:443-53.

17. Ah Young Kang, Su Kyung Park, So Young Park, et al. Therapeutic Target Achievement in Type 2 Diabetic Patients after Hyperglycemia, Hypertension, and Dyslipidemia Management. Korean Diabetes Association. Diabetes Metab J 2011; 35:264-272

18. Lee JE, Park HA, Kang JH, et al. State of diabetes care in Korean adults: according to the American Diabetes Association Recommendations. J Korean AcadFam Med 2008; 29:658-67.

19. Lim DJ, Kwon HS, Kim HS, et al. Clinical characteristics of the diabetic patients managed at the different medical institutions in Seoul and Gyeonggi province. Korean J Med 2006; 71:173-81. 